\title{
CONSTITUCIONALISMO LATINO-AMERICANO E O RECONHECIMENTO DE DIREITOS LGBTI
}

\author{
LATIN-AMERICAN CONSTITUTIONALISM AND THE RECOGNITION \\ OF LGBTI RIGHTS
}

\begin{abstract}
Rafael Carrano Lelis
Mestrando em Direito pela Pontifícia Universidade Católica do Rio de Janeiro - PUC-Rio.

E-mail: rafael.carrano.lelis@gmail.com

Joana de Souza Machado

Professora Adjunta da Universidade Federal de Juiz de Fora - MG. Doutora e Mestre em Direito pela Pontifícia Universidade Católica do Rio de Janeiro (PUC-Rio), com estágio doutoral, com bolsa CAPES, junto à Harvard Law School e atuação como pesquisadora visitante na Boston College Law School. Possui graduação em Direito pela Universidade Federal de Juiz de Fora. E-mail: joanajf@yahoo.com
\end{abstract}

Recebido em: 28/02/2019

Aprovado em: 02/09/2020

RESUMO: O trabalho investiga a proteção constitucional dos direitos LGBTIs na América do Sul e no México. Partindo do marco-teórico da justiça democrática pós-westfaliana, de Nancy Fraser, questiona-se se a tutela constitucional desses direitos nos referidos países é suficiente para que se avance na concretização da justiça para as pessoas LGBTIs. Utilizando-se as técnicas de revisão bibliográfica e análise documental, são explorados os textos constitucionais de 13 países latinoamericanos na busca por direitos específicos, guiando-se por categorias de análise. Ao final, concluiu-se pela insuficiência da tutela, em virtude da precária positivação constitucional e da alta dependência de decisões judiciais para a efetivação de direitos.

Palavras-chave: Direito Constitucional. Direitos LGBTIs. Constitucionalismo Latino-Americano.

ABSTRACT: The study investigates the constitutional protection of LGBTI rights in South America and Mexico. Under the theoretical framework of Nancy Fraser's postwestphalian democratic justice, it interrogates whether the constitutional protection of these rights in such countries is sufficient in order to move forward towards the accomplishment of justice to LGBTI people. Through the use of the techniques of literature review and documental analysis, the paper explored the constitutional text of 13 latin-american countries searching for specific rights and guided by analytical categories. In the end it was possible to conclude that the constitutional protection is unsatisfactory, given the precarity of the constitutional norms, as well as the high dependence on judicial decisions to implement rights.

Keywords: Constitutional Law. LGBTI Rights. Latin-American Constitutionalism. 
SUMÁRIO: Introdução. 1 A teoria da justiça democrática Pós-Westfaliana de Nancy Fraser. 2 Metodologia e análise das constituições. 2.1 O Uso de Linguagem Inclusiva de Gênero no Texto Constitucional. 2.2 Vedação à Discriminação de LGBTIs. 2.3 Direito à União Civil. 2.4 Demais previsões. Conclusão. Referências.

\section{INTRODUÇÃO}

A violência contra lésbicas, gays, bissexuais, trans e intersexuais (LGBTIs) ocorre de forma generalizada e, em grande parte dos casos, institucionalizada. De acordo com relatório da International Lesbian, Gay, Bissexual, Trans and Intersex Association (ILGA), a existência LGBTI ainda é criminalizada em 72 países, em suas diversas formas possíveis de manifestação (CARROLL; MENDOS, 2017, p. 70-146). A punição é severa na maioria dos casos, incluindo penas de morte e prisões perpétuas.

A percepção dessa violência de maneira concreta é extremamente difícil. Isso se deve, principalmente, a dois motivos: à ausência de denúncias e à falta de estatísticas oficiais (CIDH, 2015, p. 81-83). Não obstante, de acordo com a Comissão Interamericana de Direitos Humanos (CIDH, 2015, p. 93), "pelo menos 594 pessoas LGBT ou percebidas como tal foram assassinadas em ataques aparentemente relacionados com a percepção sobre sua orientação sexual ou sua identidade e expressão de gênero" nas américas, no período de 15 meses, compreendido entre janeiro de 2013 e março de 2014.

O Brasil ocupa uma posição nada louvável nesse cenário. Conforme levantamento do Grupo Gay da Bahia (GGB, 2017, p. 5), ele é o país que mais mata LGBTIs no mundo, com uma morte a cada 19 horas. Suas pesquisas indicaram 445 LGBTIs vítimas de homicídio em 2017, um aumento de $30 \%$ com relação ao ano anterior e o mais alto índice registrado desde o início da coleta dos dados, em 2000. Ainda sobre a violência no país, estudo realizado pela organização Transgender Europe (TGEU, 2016, p. 2) aponta que, só no Brasil, foram identificados 845 assassinatos de pessoas trans entre 2008 e 2016, o que corresponde a cerca de $40 \%$ do total mundial no período, que foi de 2.115 mortes.

Embora o avanço no campo jurídico não seja, de forma isolada, suficiente para superar esse cenário, a previsão de direitos é um fator necessário para que se aproxime da concretização da dignidade e justiça para os LGBTIs. Nesse sentido, as normas possuem um grande poder simbólico, que efetiva o reconhecimento dessas pessoas. Por isso, a partir do marco teórico da justiça democrática pós-westfaliana, proposta por Nancy Fraser, o problema central desta pesquisa indaga se a proteção constitucional dos direitos LGBTIs na América Latina é suficiente. A hipótese inicial, sustentada nos números registrados de violência e assassinatos cometidos contra essa população, indica que a tutela seria insuficiente, por não conseguir protegê-los desses acontecimentos.

Para a testagem da hipótese, adotou-se uma abordagem imaginativa de direito comparado, conforme proposto por Geoffrey Wilson (2007, p. 97-101). De acordo com o autor, diferentemente do direito comparado tradicional, que se limita à comparação dos textos e sistemas legais para sua melhor compreensão; uma abordagem que se valha de uma "imaginação informada" não se limita a métodos tradicionais e nem ao que é formalmente designado como direito, preocupando-se com o aspecto social da pesquisa.

Para o desenvolvimento da investigação, foram utilizadas as técnicas de revisão bibliográfica e análise documental, visando à construção de uma pesquisa empírica de caráter eminentemente qualitativo, ainda que em alguns momentos tenham sobressaído elementos quantitativos. A revisão bibliográfica foi utilizada para a melhor compreensão do marco teórico adotado, bem como para a obtenção de dados secundários com relação à proteção dos direitos LGBTIs. A análise documental, por sua vez, consistiu no exame das constituições dos países da América do Sul e do México, na busca por proteção de direitos específicos para os e as LGBTIs. Foi excluído o exame jurisprudencial, pois se considera que a ausência de previsão no texto 
constitucional já configura uma insuficiência protetiva, uma vez que a positivação constitucional dos direitos é considerada essencial para a efetivação de seu valor simbólico, bem como para a garantia de maior segurança jurídica.

O recorte regional foi estabelecido em virtude de características específicas do constitucionalismo latino-americano ${ }^{1}$. Nesse sentido, Leonardo Avritzer (2017, p. 28) defende que o Novo Constitucionalismo Latino-Americano (NCLA) possuiria três características principais. Seriam elas: 1) a forte ampliação de direitos, isto é, constituições com pautas substantivas alargadas; 2) a expansão das formas de participação, principalmente por mecanismos democráticos de participação popular direta e indireta; 3) o exercício de um novo papel pelo Poder Judiciário. O autor aponta, ainda, que essa nova forma de constitucionalismo se distingue pela grande ampliação do reconhecimento de direitos a categorias historicamente oprimidas, avançando, por exemplo, na proteção das comunidades tradicionais e das mulheres (AVRITZER, 2017, p. 28-29). Assim, o NCLA parece um cenário extremamente propício à concretização dos direitos LGBTIs. Desse modo, sua análise pretende não só averiguar se essa "forte ampliação de direitos" abarcou inclusive as pessoas LGBTIs, mas também traçar um panorama da atual fase de tutela desses direitos, a partir de um cenário constitucional no qual eles deveriam, em tese, estar mais avançados.

Desse modo, o objetivo geral do trabalho era descobrir a extensão e a forma da proteção constitucional dos direitos de pessoas LGBTIs na América do Sul e no México. Ademais, a pesquisa possuía como objetivos específicos: 1) a realização de ampla revisão bibliográfica sobre teorias da justiça e do reconhecimento; bem como a revisão e leituras pontuais de textos a respeito da interpretação constitucional, da teoria queer, do constitucionalismo latino-americano e dos direitos das pessoas LGBTIs; 2) a leitura e exame dos textos constitucionais dos países sulamericanos e do México.

\section{A TEORIA DA JUSTIÇA DEMOCRÁTICA PÓS-WESTFALIANA DE NANCY FRASER}

Filósofa política que aborda assuntos como justiça e democracia, Nancy Fraser (2010, p. 145) construiu uma teoria tridimensional, que comporta três planos para a concretização da justiça, efetivando a paridade participativa: o econômico, o cultural e o político. Inicialmente pensada apenas com a duas primeiras facetas, a dimensão política foi recentemente alçada a uma categoria autônoma, respondendo a anseios causados pelo atual estágio de globalização.

Dessa forma, cada uma dessas dimensões possui seus níveis de justiça e injustiça correspondentes. A injustiça de ordem econômica se materializa por meio da má distribuição; a cultural, pela via do falso reconhecimento; e a política se concretiza na falsa representação. Como destaca a autora, esses três aspectos são essenciais à compreensão dos meios de obtenção da justiça. Ainda que, em determinados contextos, possa-se perceber a prevalência de algum dos tipos de injustiça, é necessário considerar que os três formam um conjunto interdependente, não podendo nenhuma das camadas ser reduzida à injustiça gerada pela outra (FRASER, 2008, p. 16).

A dimensão econômica da justiça é representada pela ideia de distribuição de bens, recursos e riquezas que geram as diferenças de classe e promovem a exploração do trabalho no mundo capitalista. São exemplos desse nível de injustiça: a exploração econômica dos trabalhadores pelas empresas, que lucram com o trabalho de determinada camada da população; e a negação a determinadas pessoas de usufruir dos bens materiais ofertados pelo mercado, que, em muitas das vezes, foram produzidos justamente por elas próprias enquanto trabalhadoras (FRASER, 2008, p. 14).

Como mencionado, a segunda dimensão responsável pela concretização da justiça é a cultural, na qual se enquadram as demandas pelo reconhecimento de cada uma das camadas desprezadas. Desse modo, Fraser (2000, p. 113-116) propõe uma abordagem baseada na

\footnotetext{
${ }^{1} \mathrm{O}$ novo constitucionalismo foi o ponto de partida para o recorte, que acabou englobando outros países da região, que não necessariamente compartilham da mesma tradição constitucional.
}

Revista de Direito Brasileira | Florianópolis, SC | v. 26 | n. 10 | p. 46-65 | Mai./Ago. 2020 
conceituação do reconhecimento enquanto uma questão de status social. A partir desse critério, o falso reconhecimento se traduziria como uma forma de subordinação social. Nesse sentido, o conceito se relaciona à reprodução institucionalizada de padrões de subordinação que impedem a paridade participativa de determinados indivíduos na vida social. Nesse cenário, o fator institucional é essencial para a caracterização da injustiça do falso reconhecimento, que acontecerá por meio da estigmatização de determinadas pessoas como inferiores, excluindo-as da e invisibilizando-as na interação social (FRASER, 2000, p. 113).

Uma das possibilidades mais prementes dessa institucionalização é pela via jurídiconormativa. Nesse sentido, leis que categorizam determinados atores sociais como inferiores ou transgressores (em contraposição aos demais, que estariam dentro da norma social) provocam a subordinação de status. Ademais, isso também ocorre quando a legislação, desconsiderando a própria possibilidade de existência de determinados indivíduos (posicionando-os como não seres), deixa de considerá-los na edição normativa, criando lacunas que impeçam sua participação na vida social. À guisa de exemplificação, temos: uma lei proibindo o casamento entre pessoas do mesmo gênero incorre nesse tipo de injustiça; contudo, também o faz a lei que regulamenta somente a união heteroafetiva, ignorando a própria existência de outros arranjos familiares e permanecendose silente com relação a eles.

Fraser aponta que a raiz da injustiça contra gays e lésbicas (as sexualidades desprezadas) estaria na dimensão cultural, de modo que ela se reproduz por meio de padrões sociais institucionalizados e reiterados, e não a partir da divisão do trabalho. Por isso, Fraser (2008, p. 21) caracteriza a homofobia como a "desvalorização cultural da homossexualidade", enquanto o heterossexismo seria a reafirmação dos privilégios heterossexuais por meio da edição de normas que os imponham. Tal situação é facilmente aferível por meio dos inúmeros direitos que são negados a essa coletividade, bem como das frequentes situações sociais nas quais essas sexualidades são alvo de discriminação, violência, hostilização e humilhação. Exatamente por isso, Fraser (2010a, p. 173) destaca que "a superação da homofobia e do heterossexismo requer uma modificação na ordem do status sexual, desinstitucionalizando os padrões heteronormativos de valor, substituindo-os por padrões que expressem igual respeito para com gays e lésbicas".

Finalmente, analisados os aspectos cultural e econômico da justiça, passa-se à última das dimensões idealizadas por Fraser: a política. Segundo a autora, a dimensão política serve de arena ("stage") para que sejam debatidas e proferidas as demandas por redistribuição e por reconhecimento. Nesse sentido, ela é responsável pelo estabelecimento dos procedimentos por meio dos quais tais demandas poderão ser legitimamente veiculadas.

A concretização da justiça política ocorre por meio da representação. A injustiça nessa dimensão é, portanto, a da falsa representação. Sob esse aspecto, Fraser (2010, p. 18-23) distingue dois níveis de falsa representação: um primeiro relacionado à falsa representação político-comum ("ordinary-political misrepresentation"), abarcando questões já conhecidas relativas a regras eleitorais; e um segundo ligado ao que ela denominou de "mau enquadramento" ("misframing"), remetendo às fronteiras da política e da própria justiça, que pode ser identificado em discussões, por exemplo, acerca da extensão de determinada jurisdição.

Tendo em vista a realidade de injustiças, dois são os remédios possíveis à solução da desigualdade: afirmativo ou transformativo. Segundo Fraser (2008, p. 28), remédios afirmativos, de forma geral, seriam aqueles voltados à correção de iniquidades com os instrumentos fornecidos pelo próprio sistema vigente; isto é, com a utilização de ferramentas disponíveis dentro da estrutura que causa a iniquidade. Esse tipo de remédio possui, claramente, escopo de atuação limitado, uma vez que não pretende alteração substancial do status quo, almejando apenas um pequeno avanço na realidade social. Por outro lado, um remédio transformativo almeja justamente o contrário: a correção dos resultados desiguais a partir da reestruturação do quadro que os gera. É importante notar que a diferença entre os tipos de remédios não se dá em razão de sua aplicação de forma gradual ou não, mas sim no fato de o primeiro focar na alteração apenas dos resultados, 
enquanto o segundo busca a sua modificação por meio da alteração dos processos que levaram a tais resultados.

\section{METODOLOGIA E ANÁLISE DAS CONSTITUIÇÕES}

Epstein e King (2013, p. 47-56) apontam a "replicabilidade" como regra essencial a ser observada pelo investigador na pesquisa empírica. Desse modo, é essencial a exposição, de forma minuciosa, de como se deu a coleta dos dados utilizados na pesquisa. Nesse sentido, os autores apontam que "o bom trabalho empírico adere ao padrão da replicação: outro pesquisador deve conseguir entender, avaliar, basear-se em, e reproduzir a pesquisa sem que o autor lhe forneça qualquer informação adicional". Por isso, dedica-se esta seção à explicitação da forma de coleta de dados realizada na análise documental.

Inicialmente, o objeto de pesquisa do trabalho era bastante amplo: analisar todas as constituições latino-americanas, incluindo as dos países da América do Sul, da América Central (ou caribenha) e o México. No entanto, à medida que foi sendo realizada a coleta dos dados, percebeu-se que o objeto definido era demasiadamente extenso, o que impediria, por questões de tempo, uma análise pormenorizada e crítica das informações obtidas. Sendo assim, um tanto quanto arbitrariamente, em virtude das limitações temporais e financeiras do trabalho, optou-se por examinar as constituições dos países da América do Sul e a do México. Principalmente, por se entender que a tradição constitucional desses países guarda maiores semelhanças entre si, do que com aquela dos caribenhos, tendo em vista a composição do NCLA, ainda que nem todos os países analisados se enquadrem na referida tradição constitucional ${ }^{2}$.

Dentro desse recorte geográfico, excluiu-se ainda a análise das Ilhas Malvinas, das Ilhas Geórgia do Sul e Sandwich do Sul e da Guiana Francesa. Isso porque as duas primeiras estão sob a jurisdição do Reino Unido, enquanto a última se submete ao ordenamento francês. Desse modo, como o objetivo é traçar um panorama da proteção na América Latina, não cabe o exame de suas cartas constitucionais. Assim, restou um total de treze países contemplados pela pesquisa, sendo eles: Argentina, Bolívia, Brasil, Chile, Colômbia, Equador, Guiana, México, Paraguai, Peru, Suriname, Uruguai e Venezuela.

O texto de cada uma dessas constituições foi obtido em sites oficiais do legislativo ou executivo dos referidos Estados; ou, quando não estava disponível nesses meios, no site da Organização dos Estados Americanos (OEA). O acesso a esses documentos e seu arquivamento foram realizados entre 12 e 18 de novembro de 2017, de modo que foram apreciadas apenas as emendas constitucionais aprovadas até esse período.

Devido a possíveis ambiguidades ou alterações de sentido a partir de traduções, optou-se pela leitura dos textos em sua língua original; havendo, entretanto, uma exceção. Tendo em vista o idioma oficial do Suriname, o Neerlandês, e diante da falta de domínio do referido vernáculo, foi necessária a utilização de versão traduzida para o inglês, disponibilizada pela Unesco ${ }^{3}$.

Com relação ao método, guiou-se pela análise qualitativa tripartite de documentação empírica proposta por Mario Cardano (2017). O método de análise proposto pelo autor compreende as seguintes etapas: segmentação, qualificação e individuação das relações. A segmentação se refere ao estabelecimento de marcadores, "cuja função consiste na identificação de segmentos relativamente homogêneos para submeter à comparação no interior dos materiais empíricos" (CARDANO, 2017, p. 273). Nesse sentido, foi realizada a leitura integral de todas as constituições, na busca da previsão de direitos específicos, mas guiada por três critérios a serem especialmente

\footnotetext{
${ }^{2}$ Apesar de não haver uma classificação uníssona sobre quais constituições entrariam ou não na referida corrente, a literatura especializada é unânime em apontar as cartas constitucionais de Bolívia e Equador como as maiores representantes do referido movimento. Nesse sentido ver: (SANTOS, 2010) e (VIEIRA et al, 2013).

3 Essa versão traduzida per encontrada <http://www.unesco.org/education/edurights/media/docs/dfcff4209dad7879549a7d46dc0bcbf82919c591.pdf>.
} Revista de Direito Brasileira | Florianópolis, SC | v. 26 | n. 10 | p. 46-65 | Mai./Ago. 2020 
observados, formando a segmentação. São eles: 1) a utilização de linguagem inclusiva de gênero; 2) a vedação à discriminação de LGBTIs; 3) a possibilidade de união civil entre pessoas do mesmo gênero. Além dos motivos peculiares a cada um desses critérios, que serão explicados à frente, os três foram escolhidos devido à maior facilidade de percepção de sua presença (ou ausência) no texto positivo.

Mais adiante, a etapa da qualificação é conceituada por Cardano (2017, p. 293) como a "atribuição de uma ou mais propriedades a um determinado segmento da documentação empírica, úteis à sua caracterização". Desse modo, a técnica permite que se aprofunde a dimensão de análise do documento por meio de sua maior especificação. Portanto, para a qualificação dos segmentos, utilizou-se a chamada template analysis proposta por Nigel King (2012, p. 426-450). O método consiste na composição de uma grade analítica a partir da caracterização de cada uma das propriedades identificadas para possibilitar sua comparação. A utilização da template analysis pode se dar a partir de duas abordagens principais: indutiva (data-driven), sendo a grade composta por meio do observado na análise do material; ou dedutiva (theory-driven), por meio da qual se encaixa o encontrado no documento analisado a categorias definidas previamente. Na análise das constituições, utilizou-se uma abordagem indutiva nos segmentos referentes à não discriminação e à linguagem inclusiva (na segunda, valendo-se da consideração, também, de ausências textuais); e dedutiva no caso da união civil, observando-se uma categorização previamente estabelecida.

Por fim, a individuação das relações consiste na análise a partir da comparação das qualificações; ou, ainda, por meio da separação de determinada qualificação para análise. Sendo assim, nessa última etapa, realizou-se a análise por meio do exame cruzado das qualificações e, também, dos casos desviantes, destrinchando a sua distinção com relação aos demais.

\subsection{O Uso de Linguagem Inclusiva de Gênero no Texto Constitucional}

O argentino Daniel Borrillo (2016) se debruçou profundamente sobre o estudo da homofobia $^{4}$ e suas diversas formas de manifestação. Em seu trabalho, o autor busca categorizar alguns dos principais tipos de expressão desse preconceito, merecendo destaque as diferenciações entre homofobia irracional e cognitiva; e entre homofobia geral e específica. Neste momento, interessa-nos, especialmente, a ideia construída pelo autor com relação à homofobia em sua perspectiva geral.

Segundo ele, as práticas homofóbicas estão intrinsecamente ligadas ao sexismo profundamente instaurado em nossa sociedade, por meio do qual são naturalizados papeis de feminino e masculino. Uma ordem sexual que "implica tanto na (sic) subordinação do feminino ao masculino, quanto a hierarquização das sexualidades" (BORRILLO, 2016, p. 30). Desse modo, a homofobia, em seu aspecto mais geral, seria produto do padrão machista, que hostiliza aqueles e aquelas que não se adequam à função de seu gênero atribuído, de macho ou fêmea. Assim, gays e lésbicas, ao assumirem algumas das características do gênero originalmente oposto (como o desejo sexual) rompem essa barreira, o que provoca a desaprovação social. Ainda mais escancaradas, sob a lógica sexista, são as pessoas trans e intersexuais que efetivamente transgridem, por completo, a norma que generifica nossa sociedade.

Nesse sentido, se uma das formas de exteriorização do preconceito contra LGBTIs é o machismo, seria coerente pensar que aquelas sociedades - neste caso representadas por seus ordenamentos jurídicos - que se demonstram mais avançadas no combate à desigualdade de gênero, também estariam mais perto do reconhecimento dos direitos das pessoas LGBTIs.

Por esse motivo, adotou-se a utilização de linguagem inclusiva de gênero no texto constitucional como um dos critérios a ser analisado. Importante notar que a adoção desse tipo de linguagem demonstra um compromisso ainda maior com o rompimento da barreira da desigualdade

\footnotetext{
${ }^{4}$ A ideia de homofobia elaborada pelo autor é ampla o suficiente para abarcar potencialmente todas as formas de preconceito LGBTIfóbicas.
}

Revista de Direito Brasileira | Florianópolis, SC | v. 26 | n. 10 | p. 46-65 | Mai./Ago. 2020 
de gênero do que a mera previsão de direitos para as mulheres, por exemplo. Isso porque implica alteração na estrutura linguística enraizada que historicamente valoriza a predominância masculina, sobretudo nas línguas de origem latina. Inúmeras são as legislações que preveem direitos específicos para as mulheres; poucas, entretanto, são aquelas que permitem o rompimento da barreira da linguagem, que exerce, cotidianamente, violência simbólica sobre elas.

Merece atenção, ainda, o fato de o critério eleito ser a observância ou não de uma linguagem inclusiva de gênero; e não de uma linguagem neutra de gênero. Trata-se, a linguagem inclusiva, daquela que procura demarcar textualmente as palavras tanto no gênero masculino, quanto feminino. Algo semelhante ao que tem sido feito neste texto, em diversos momentos, como ao se referir a "negros e negras" (e não apenas a "negros"), ou "às e aos LGBTIs" (e não apenas "aos" LGBTIs). Por outro lado, a linguagem neutra de gênero exigiria do legislador um esforço subversivo muito maior; o que, obviamente, não foi encontrado em nenhum dos textos. Essa segunda modalidade demandaria a abstenção total da utilização dos marcadores tradicionais dos gêneros feminino e masculino. Isto é, ou a utilização apenas de termos que não possuem essa designação (como "pessoas") ou a substituição dos marcadores tradicionais por um único alternativo (como a utilização do "x" ou do "e" nas palavras).

Dessa forma, destaca-se que, apesar de um grande avanço, a linguagem inclusiva não é o patamar final ideal. Isso porque, embora solucione a subordinação linguística do feminino frente ao masculino, ainda mantém uma lógica binária, excluindo todas as demais formas de expressão de gênero que não se enquadrem nessas categorias.

Diante dessas observações, salienta-se que o objetivo, neste momento, era identificar se existe alguma relação entre a utilização da linguagem inclusiva de gênero (que representa o avanço da superação da desigualdade entre homens e mulheres) e a proteção dos direitos LGBTIs. A hipótese era que um ordenamento com tamanho grau de evolução (a ponto de modificar a linguagem utilizada) também seria mais sensível à temática de orientação sexual e identidade de gênero.

Para verificar a procedência ou não de tal hipótese, valeu-se das regras de inferências definidas por Epstein e King (2013, p. 36-47), mais especificamente na tentativa de estabelecimento de uma inferência causal. Segundo os autores, a inferência é o "processo de utilizar fatos que conhecemos para aprender sobre os fatos que desconhecemos". A inferência causal, por sua vez, consiste nesse mesmo processo a partir de conjugação de duas variáveis diferentes: uma variável dependente (que seria, no caso em tela, o avanço na proteção de direitos LGBTIs, representado pelo preenchimento ou não dos critérios de união civil e não discriminação); e uma variável principal (que no caso seria o avanço no combate à desigualdade de gênero, representado pela utilização da linguagem inclusiva de gênero). Desse modo, a correspondência do efeito causal se dá por meio da análise de se a introdução ou retirada da variável principal causa alguma alteração nas variáveis dependentes. Em nosso contexto, é dizer: se a utilização de linguagem inclusiva de gênero pela Constituição ocasiona a também previsão de direitos à população LGBTI.

A aferição desse critério se deu por meio da constatação da utilização, de forma recorrente e ao longo de todo o texto constitucional, das duas designações de gênero, por exemplo: "cidadãs e cidadãos", "extranjeros y extranjeras", "his and hers"; em detrimento de apenas "cidadãos", "extranjeros", "his".

Após esse exame, identificou-se que apenas 30,77\% das constituições investigadas adotaram tal modalidade de linguagem. Isso corresponde a um total de quatro países. São eles: Bolívia, Equador, Guiana e Venezuela. Posteriormente, para testagem da hipótese inicial, conjugou-se esse com os demais critérios de análise (vedação à discriminação e possibilidade de união civil). Assim, intentava-se detectar se, como esperado, esses quatro países teriam um resultado também positivo nos dois demais parâmetros. 
Infelizmente, não foi o que aconteceu. Como evidenciado pela Tabela 1, dentre os quatro países, apenas os textos constitucionais da Bolívia e do Equador possuem previsão que veda a discriminação a LGBTIs.

Além disso, as Cartas Magnas dos três países de língua latina preveem expressamente que o casamento ocorre entre "un hombre y una mujer" (ou vice-versa). Quadro que se repete na previsão da união estável, com exceção da Constituição equatoriana, que, nesse tipo de união civil, identifica que seria um vínculo entre "personas".

Tabela 1 - Relação da Proteção Constitucional dos Direitos LGBTIs entre os Países que Utilizam Linguagem Inclusiva de Gênero

\begin{tabular}{|c|c|c|c|}
\hline \multirow[t]{2}{*}{ País } & \multirow{2}{*}{$\begin{array}{l}\text { Previsão de } \\
\text { Vedação à } \\
\text { Discriminaçã } \\
\text { o LGBTI }\end{array}$} & \multicolumn{2}{|r|}{ União Civil } \\
\hline & & Casamento & $\begin{array}{c}\text { União Estável (uniones de } \\
\text { hecho) }\end{array}$ \\
\hline Bolívia & $\begin{array}{l}\text { Sim (em } \\
\text { razão de } \\
\text { orientação } \\
\text { sexual e } \\
\text { identidade de } \\
\text { gênero) }\end{array}$ & $\begin{array}{l}\text { Entre "una } \\
\text { mujer y un } \\
\text { hombre" }\end{array}$ & Entre "una mujer y un hombre" \\
\hline Equador & $\begin{array}{l}\text { Sim (em } \\
\text { razão de } \\
\text { orientação } \\
\text { sexual, } \\
\text { identidade de } \\
\text { gênero e } \\
\text { portador de } \\
\text { HIV) }\end{array}$ & $\begin{array}{l}\text { Entre } \\
\text { "hombre y } \\
\text { mujer" }\end{array}$ & Entre "dos personas" \\
\hline Guiana & Não & $\begin{array}{l}\text { Sem } \\
\text { regulamentaçã } \\
\text { o }\end{array}$ & Sem regulamentação \\
\hline Venezuela & Não & $\begin{array}{l}\text { Entre "un } \\
\text { hombre y una } \\
\text { mujer" }\end{array}$ & Entre "un hombre y una mujer" \\
\hline
\end{tabular}

Fonte: autoria própria

No caso da Guiana, apesar de não haver regulamentação constitucional da união civil, o ordenamento é ainda mais drástico em rechaçar qualquer forma de relacionamento entre pessoas do mesmo gênero. A legislação do país optou ${ }^{5}$ pela criminalização de condutas homossexuais; ou, mais especificamente, gays, uma vez que o dispositivo legal se refere notadamente à interação entre dois homens.

\footnotetext{
${ }^{5}$ Importante notar que a Guiana, ex-colônia inglesa, soma ao perfil de países da commonwealth britânica que herdaram de seus colonizadores leis que criminalizam relações homossexuais, sendo essa a origem da maioria das normativas atualmente vigentes que criminalizam o sexo consentido entre homens adultos (WINTEMUTE, 2011, p. 40-45). No caso da Guiana a situação é ainda mais grave, diante da existência da chamada "saving law clause" no artigo 152 de sua Constituição. A norma, que foi exigência dos britânicos no processo de independência, impede o questionamento da constitucionalidade das leis do período colonial com base na violação a direitos fundamentais. E, ainda, diferentemente do cenário de outros países (como Belize), não há qualquer "prazo de validade" para que a "saving law clause" perca sua aplicabilidade (BURNHAM, 2005, p. 250-252).
} 
Sendo assim, é evidente que, não obstante o avanço desse ordenamento com relação à diminuição da desigualdade de gênero, o cenário para a população LGBTI é tenebroso. Diferentemente da maioria dos casos, a relação homossexual é reprimida não só no âmbito público, mas também no privado. Além disso, optou-se por realizar tal repressão por meio do direito penal, o que agrava seu caráter, criminalizando a existência desses indivíduos. Gays e bissexuais são proibidos de amar e se relacionar, têm retirada toda sua dignidade e podem ser punidos com pena perpétua por algo inerente à sua própria existência; algo que não pode, voluntariamente, ser alterado: sua sexualidade, seu desejo por outros seres humanos.

Com efeito, a hipótese inicialmente pensada não se demonstrou no caso concreto, não sendo possível traçar a inferência pretendida. É dizer: não parece haver relação necessária entre o avanço do combate à desigualdade de gênero e a previsão de direitos específicos para as e os LGBTIs. Todavia, o raciocínio oposto é corroborado pelos dados. Os dois países cuja proteção constitucional de LGBTIs demonstrou ser a mais abrangente e avançada (como será apresentado à frente) são, justamente, Equador e Bolívia, dois ordenamentos que adotam linguagem inclusiva de gênero em seu texto constitucional. Portanto, se o avanço em direitos das mulheres não pressupõe que o mesmo sistema jurídico terá sensibilidade com questões de orientação sexual e identidade de gênero; por outro lado, o avanço na seara LGBTI ocorre em ordens jurídicas nas quais já existe uma consolidação, pelo menos positivada, de direitos específicos para as mulheres, atenuando a desigualdade de gênero. Ressalva-se, contudo, que tal inferência não deve ser levada de forma categórica, sendo apenas uma tendência ilustrada, tendo em vista que a reduzida amostragem não permite qualquer afirmação categórica.

\subsection{Vedação à Discriminação de LGBTIs}

O segundo critério eleito para a análise dos documentos foi a presença ou não de cláusulas que vedem a discriminação à população LGBTI. O direito fundamental à não-discriminação deriva diretamente do direito à igualdade, sendo pressuposto necessário para a efetivação e o usufruto de todas as demais garantias individuais, assegurando tratamentos jurídico e social isonômicos. Nessa perspectiva, a vedação à discriminação (em seu aspecto arbitrário) é o mais básico dos direitos necessários à superação das injustiças de reconhecimento e de representação, efetivando a paridade de participação.

Nessa linha, Bandeira de Mello (2010, p. 45) aponta que "a isonomia se consagra como um dos maiores princípios garantidores dos direitos individuais". Desse modo, sem isonomia não há como se avançar na previsão de outros direitos específicos, o que também não pode ser feito sem a salvaguarda da não-discriminação. É justamente por isso que foi escolhido tal critério: por considerá-lo o ponto de partida para garantias mais profundas e completas, uma vez que ele é o patamar fundante (ainda que precário) das demais previsões normativas que possam se voltar às pessoas LGBTIs.

Partindo para a análise documental propriamente, procurou-se identificar a menção de marcadores como "orientação sexual" ou "identidade de gênero" (e suas possíveis variantes) dentre o elenco de motivos pelos quais se pró́be um tratamento diferencial ou discriminatório. Não obstante tenha se procurado por esses marcadores, destaca-se que um texto mais progressista e inclusivo deveria vedar a discriminação também com base em "expressão de gênero" e "características sexuais" (sex characteristics), abarcando de formas mais abrangente outros tipos de discriminação, principalmente contra pessoas intersexo e não binárias ${ }^{6}$.

Importa notar que há interpretações, como a proposta por Roger Raupp Rios (2010, p. 704-705), de enquadramento da discriminação por orientação sexual e identidade de gênero enquanto tratamento proibido pelo mandamento constitucional que veda a discriminação em razão

${ }^{6}$ É o que sugere, por exemplo, o documento "The Yogyakarta Principles plus 10” (2017).

Revista de Direito Brasileira | Florianópolis, SC | v. 26 | n. 10 | p. 46-65 | Mai./Ago. 2020 
do sexo. Para tanto, o autor defende que os homossexuais são discriminados devido ao sexo da pessoa para quem dirigem seu desejo; ou seja, por sentirem atração por alguém do mesmo sexo. Segundo ele, portanto, essa seria uma discriminação, antes de tudo, fundada na diferenciação (ou não) dos sexos. Da mesma forma, indica que as pessoas trans sofrem discriminação por não se enquadrarem na perspectiva biomédica e binária de definição sexual, tendo sua identidade de gênero rechaçada, justamente devido a uma compreensão das possibilidades de enquadramento do sexo dos indivíduos.

Não obstante, embora não se negue a importância da teoria desenvolvida por Raupp e também do seu potencial de proteção jurídica de LGBTIs, não será considerado o marcador "sexo" como abarcando a vedação de discriminação a LGBTIs. Isso porque, como anteriormente abordado, pretende-se identificar formas de tutela direta das garantias, a partir da previsão de direitos específicos, e a previsão de vedação à discriminação em razão de sexo não é direcionada especificamente às pessoas LGBTIs.

Dessa forma, em um primeiro exame das cartas constitucionais, constatou-se que apenas $23 \%$ dos países possuem previsão expressa que proíbe, em alguma medida, discriminação contra LGBTIs. Isso corresponde a apenas três, dentre os treze analisados, o que se demonstra um número demasiadamente ínfimo no universo estudado, conforme explicita o Gráfico 1.

\section{Gráfico 1 - Vedação à Discriminação LGBTI nas Constituições}

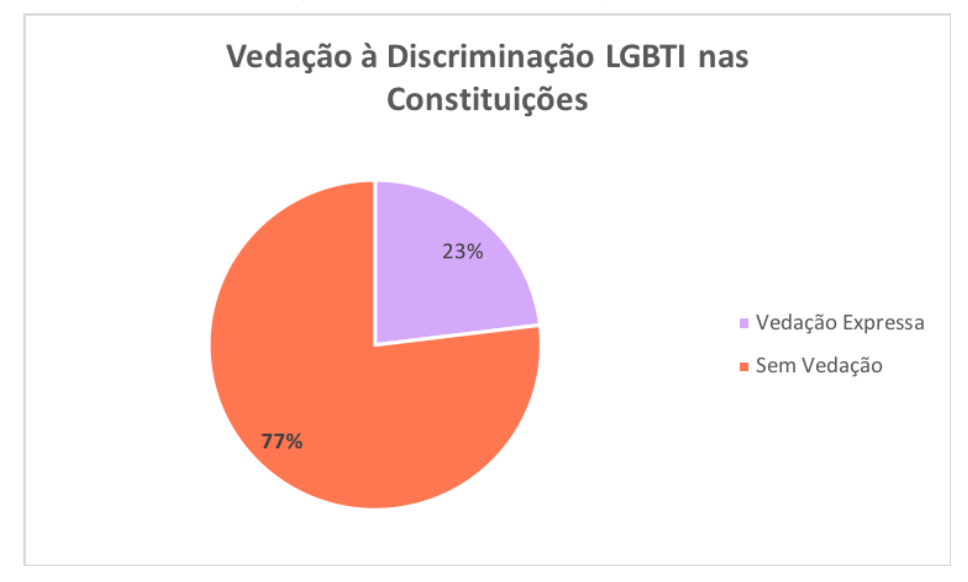

Fonte: autoria própria

Não obstante, os dados coletados merecem um tratamento mais atento e detalhado. Nesse sentido, dividiram-se as previsões constitucionais em quatro categorias, que são detalhadas na Tabela 2. A primeira delas se refere à proibição de discriminação em razão de orientação sexual e de identidade de gênero, simultaneamente. Na segunda categoria, encaixam-se as previsões que vedam a discriminação apenas em razão da orientação sexual. A terceira classificação diz respeito aos textos que não explicitam qualquer forma de proibição de discriminação relacionada aos e às LGBTIs, apesar de o fazerem com relação a outros marcadores, como raça e gênero. Por fim, a quarta seção corresponde aos países cujos textos constitucionais optaram por não definir um rol das situações em que se veda a discriminação ou nos quais não há qualquer disposição relativa a essa categoria jurídica.

Importante notar que não há nenhuma constituição que vede a discriminação em razão da identidade de gênero, mas não o faça com relação à orientação sexual. Isso demonstra como, em geral, há mais resistência à consolidação dos direitos das pessoas trans e intersexuais; e que, aqueles ordenamentos que chegam a fazê-lo, também o fazem no tangente às pessoas lésbicas, gays e bissexuais (LGB). 
Tabela 2 - Classificação das Possibilidades de Vedação à Discriminação LGBTI por País

\begin{tabular}{|c|c|c|c|c|}
\hline Classificação & $\begin{array}{l}\text { Vedação em } \\
\text { função de } \\
\text { orientação } \\
\text { sexual e } \\
\text { identidade } \\
\text { de gênero }\end{array}$ & $\begin{array}{l}\text { Vedação } \\
\text { apenas em } \\
\text { função de } \\
\text { orientação } \\
\text { sexual } \\
\text { ("preferencias } \\
\text { sexuales") }\end{array}$ & $\begin{array}{c}\text { Ausência de } \\
\text { vedação à } \\
\text { discriminação } \\
\text { LGBTI }\end{array}$ & $\begin{array}{c}\text { Sem } \\
\text { regulamentação; } \\
\text { ou sem } \\
\text { especificação de } \\
\text { grupos }\end{array}$ \\
\hline Países & $\begin{array}{l}\text { Bolívia e } \\
\text { Equador }\end{array}$ & México & $\begin{array}{c}\text { Brasil, Colômbia, } \\
\text { Guiana, } \\
\text { Paraguai*, Peru, } \\
\text { Suriname e } \\
\text { Venezuela }\end{array}$ & $\begin{array}{c}\text { Argentina, Chile e } \\
\text { Uruguai }\end{array}$ \\
\hline
\end{tabular}

Fonte: autoria própria

Como pode ser aduzido, o exame mais detalhado dos dados demonstra, ainda mais, como a proteção dos LGBTIs nos ordenamentos latino-americanos é precária. Se a percepção inicial era que apenas três dos textos constitucionais previam cláusula vedando a discriminação LGBTI, o detalhamento dos dados indica que apenas dois desses países (Bolívia e Equador), o que equivale somente a $15 \%$ dos analisados, positivaram a proibição à discriminação com base tanto na orientação sexual, quanto na identidade de gênero. Isso porque a Constituição mexicana optou por elencar apenas o termo "preferencias sexuales", abstendo-se de reconhecer uma proteção específica às pessoas trans e intersexuais.

Neste momento, merece o Equador um destaque positivo. De longe o texto constitucional mais desenvolvido e avançado na tutela dos direitos LGBTIs, o legislador constituinte desse país optou por incluir no rol de discriminações vedadas, previsto no artigo 11, inciso dois, aquela realizada com relação às pessoas que vivem com HIV (Human Immunodeficiency Virus), no espanhol, VIH (Vírus da Imunodeficiência Humana). Embora esse direito não se dirija exclusivamente a pessoas LGBTIs, trata-se de importante acréscimo protetivo, uma vez que historicamente se estigmatiza a população LGBTI, associando-a ao vírus, que, no início da epidemia, chegou a ser equivocadamente nomeado de "praga gay" ${ }^{7}$. Desse modo, evidencia-se mais uma forma pela qual se protegem LGBTIs da discriminação.

Por outro lado, com relação ao Brasil, destaca-se que a ausência de previsão específica não se deu de forma inconsciente. Assim como ocorreu em diversos outros países, o movimento LGBTI brasileiro, encabeçado pelas organizações GGB e pelo Triângulo Rosa, trabalharam intensamente junto à constituinte para que fosse incluída a proibição de discriminação por "opção sexual" e, posteriormente, por "orientação sexual" (SIMÕES; FACCHINI, p. 122). A questão chegou a ser objeto de diversas propostas de emendas para a inclusão do termo "orientação sexual" ou "comportamento sexual" no artigo terceiro da Constituição brasileira. Nesse sentido, uma busca pelo termo "orientação sexual" nos anais da constituinte indica sua aparição 121 vezes, em quatro comissões diferentes; o que mostra que o assunto não foi simplesmente ignorado pelos legisladores ${ }^{8}$.

\footnotetext{
${ }^{7}$ No seu início em grau muito maior do que hoje, associava-se a epidemia de HIV a grupos específicos, considerados promíscuos, como os homossexuais (especialmente os gays), usuários de drogas e trabalhadores(as) do sexo. A prevenção se dava a partir da estigmatização desses grupos, que eram denominados "grupos de risco". Com o avanço da conscientização acerca das formas de transmissão do vírus e após muita luta de ativistas LGBTI, trocou-se essa definição, passando-se a conceber "comportamentos de risco", que teriam incidência geral (independentemente da orientação sexual), como a não utilização de camisinha (PAIVA, 2008, p. 642-644).

${ }^{8}$ Nesse sentido, ver: (LELIS, 2019).
}

Revista de Direito Brasileira | Florianópolis, SC | v. 26 | n. 10 | p. 46-65 | Mai./Ago. 2020 
Voltando à análise dos países que não possuem previsão, as constituições chilena, uruguaia e argentina se enquadram em uma categoria peculiar. Enquanto a lei fundamental dos dois primeiros optou por prever a vedação à discriminação sem elencar as possibilidades (ainda que exemplificativamente) nas quais se configurariam a arbitrariedade; a do último se absteve de qualquer menção ao direito antidiscriminatório.

Já aqueles posicionados na terceira coluna possuem um rol, muitos deles extensos, que indica hipóteses nas quais a discriminação é vedada. Em todos eles, sem adentrar na discussão da taxatividade ou não das possibilidades elencadas, não se inclui qualquer previsão que se refira de maneira específica aos e às LGBTIs. Em geral, as previsões proíbem a discriminação em virtude de etnia, idade, sexo, religião, filiação política, condição socioeconômica, origem nacional, condição de saúde, entres outros motivos. É pertinente notar que a Constituição da Guiana, que possui o rol mais extenso, além de não incluir questões como orientação sexual e identidade de gênero, prevê, no próprio tex to constitucional, diversas exceções ao exercício dessa garantia, o que acaba por esvaziar demasiadamente o instituto jurídico.

Ademais, no caso do Paraguai, destacado com asterisco, existe uma outra singularidade. Apesar de o artigo 46 de seu texto constitucional prever que "no se admiten discriminaciones", o elenco das possibilidades ocorre apenas na seção referente aos direitos trabalhistas (art. 88 da carta paraguaia), na qual são explicitados os casos proibitivos de discriminação.

Em suma, é evidente que o direito latino-americano ainda precisa avançar enormemente na tutela específica de um dos direitos mais básicos da população LGBTI: o direito à não discriminação, que é essencial para sejam alcançadas todas as demais garantias fundamentais desses indivíduos.

\subsection{Direito à União Civil}

O último dos três critérios adotados pelo trabalho se refere à possibilidade de união civil por casais do mesmo gênero. Além de ser o de mais difícil aferição dentre os demais, também é o mais controverso dentro do próprio movimento LGBTI, de modo que algumas ressalvas à sua escolha são necessárias.

Escolheu-se a possibilidade de união civil, pois ela ainda é, na imensa maioria dos ordenamentos jurídicos, um requisito para acesso a vários direitos por pessoas que se relacionam de forma amorosa e afetiva, como: direitos sucessórios, tributários, acesso à saúde, direitos patrimoniais, direitos previdenciários, de adoção, entre outros. Desse modo, negar o casamento ou outra forma de união civil aos LGB significa impedir seu acesso a diversos outros direitos essenciais de sua vida, e, além de tudo, ignorar o fator simbólico que representa o reconhecimento jurídico desses relacionamentos.

Não obstante, a demanda pelo reconhecimento das uniões homoafetivas como legalmente válidas pelo Estado é temática extremamente polêmica e divergem os posicionamentos de ativistas LGBTI. Ao mesmo tempo em que deve se levar em consideração o caráter simbólico dessa conquista e o acesso a direitos que ela proporciona; reivindicar esse instituto para os homossexuais significa reforçar a legitimação desse poder normalizador estatal sobre a sexualidade, passando a incluir os casais não heterossexuais no campo de permissão da norma e reforçando a exclusão de diversas outras configurações afetivas.

Alguns autores classificam essa demanda pela união e, mais especificamente, pelo casamento, como uma espécie de assimilação do movimento LGBTI das instituições e dos direitos consagrados aos heterossexuais, em detrimento de se propugnar por um rompimento mais profundo e estrutural dos fundamentos que legitimam o sistema ${ }^{9}$. Trata-se, novamente, das perspectivas entre

\footnotetext{
${ }^{9}$ É a crítica que faz Richard Miskolci (2015, p. 24), ao comparar a atuação do movimento homossexual com a do movimento queer, indicando que os primeiros estariam preocupados apenas com a incorporação social dos homossexuais; enquanto os últimos visavam modificar a sociedade mais amplamente, criticando os valores Revista de Direito Brasileira | Florianópolis, SC | v. 26 | n. 10 | p. 46-65 | Mai./Ago. 2020
} 
a definição de um remédio afirmativo, que seria a mera extensão do direito à união civil e ao casamento a gays, lésbicas e bissexuais; e um transformativo, que deveria propugnar pela dissolução da própria instituição marital e seu poder de legitimação/deslegitimação que denega direitos a indivíduos.

Desse modo, o que se buscou com a utilização desse critério é uma reivindicação consciente do direito à união civil, sem se olvidar das ressalvas necessárias. Nas palavras de Butler (2003, p. 230) "manter a tensão viva entre guardar uma perspectiva crítica e fazer uma reivindicação politicamente legível". Isto é, "sugerir uma política que incorpore uma compreensão crítica - a única que se pode reivindicar enquanto autorreflexiva e não dogmática". Dito de outro modo, a autora permite conjecturar acerca de como, politicamente, é crucial a reivindicação por inteligibilidade e reconhecimento. Ou seja, a garantia de direitos, sem os quais a própria condição de pessoa é questionada. Todavia, a ressalva de Butler se refere ao fato de a busca por legitimidade não estar excluída do jogo de poder, podendo levar a outras formas de hierarquia social e de ampliação perigosa do poder do Estado. Deslegitimando, assim, práticas sexuais vividas fora de contratos como o casamento e de suas pressuposições de monogamia. Desse modo, com o potencial de, nas palavras da autora, transformar uma deslegitimação coletiva em uma deslegitimação seletiva.

Partindo para a análise textual, diferentemente do direito à não discriminação, não se buscou uma previsão específica que reconhecesse/permitisse a união civil homoafetiva. Seria demasiado ingênuo considerar a possibilidade de que alguma constituição tenha previsto expressamente o direito de homossexuais se casarem. Por isso, o que se buscou analisar é a forma pela qual o direito ao casamento ou à união estável se apresenta no texto constitucional. Isto é, se a norma delimita o gênero dos cônjuges, atuando como uma restrição ao direito constitucional de união, excluindo homossexuais do seu âmbito de proteção; ou se a previsão se deu de forma genérica, sem a demarcação de gênero.

Para tanto, será utilizada classificação proposta por Virgílio Afonso da Silva (2014, p. 177-180), a qual abarca três possibilidades para o texto constitucional: 1) nenhuma disposição; 2) disposições específicas no que se refere ao gênero; 3) disposições neutras no que se refere ao gênero. Importa esclarecer: disposições neutras seriam o caso de nenhuma menção ao gênero feminino ou masculino, como quando se diz que o casamento se dará entre "duas pessoas". Por outro lado, a previsão específica de gênero se traduz na disposição, por exemplo, de que a união estável ocorre entre "um homem e uma mulher". Por questões didáticas, optou-se por analisar de forma separada os institutos do casamento e da união estável.

Assim, como pode ser observado nos dados apresentados na Tabela 3, com relação ao casamento, nenhuma das cartas constitucionais examinadas se enquadra na terceira hipótese de classificação. Dentre as analisadas, as constituições de pelo menos seis países não possuem disposição sobre o casamento; ou, como no caso peruano, indicam que a matéria será regulamentada por lei.

Nesse cenário, a situação do Brasil se demonstra um pouco mais complexa de se classificar. O país foi alocado na primeira coluna da tabela, mas também poderia constar da terceira. Isso porque o artigo 226 da Carta Magna do país dispõe que: "Art. 226. A família, base da sociedade, tem especial proteção do Estado. $\S 1^{\circ} \mathrm{O}$ casamento é civil e gratuita a celebração". Desse modo, ainda que haja menção ao instituto do casamento, não se alude aos sujeitos que integrariam tal união (diferentemente do que ocorre no caso da união estável), de modo que não há como se enquadrar como uma referência neutra de gênero se não há qualquer referência a indivíduos. Por

\footnotetext{
hegemônicos e buscando sua superação. No mesmo sentido, Rios (2013, p. 15) conceitua essa situação como "assimilacionismo", que se caracteriza quando "membros de grupos subordinados ou tidos como inferiores adotam padrões oriundos de grupos dominantes, em seu próprio detrimento". O autor ainda soma a esse conceito a ideia de "familismo", que define como a "tendência a subordinar o reconhecimento de direitos sexuais à adaptação a padrões familiares e conjugais institucionalizados pela heterossexualidade compulsória".
}

Revista de Direito Brasileira | Florianópolis, SC | v. 26 | n. 10 | p. 46-65 | Mai./Ago. 2020 
esse motivo, entendeu-se que o melhor seria categorizá-lo junto com aqueles que não regulamentam o instituto.

Além do Brasil, mais dois países, dentre os categorizados como "sem disposição", merecem um destaque. No caso dos textos constitucionais mexicano e surinamense, embora não haja realmente qualquer disposição sobre o casamento, os artigos $4^{\circ}$ e 35 , respectivamente, das leis fundamentais daqueles países parecem sugerir que a única composição de família admitida seria a heterossexual. Entretanto, a construção textual é aberta, deixando espaço para uma interpretação de que é, na verdade, indicada a necessidade de isonomia entre o homem e a mulher dentro do relacionamento heterossexual, como se vê nas constituições do Suriname e do México, respectivamente: "Article 35 1. The family is recognized and protected. 2. Husband and wife are equal before the law"; e "Artículo $4^{o}$. El varón y la mujer son iguales ante la ley. Esta protegerá la organización y el desarrollo de la família".

Por outro lado, todos os demais países preveem que o casamento se dá entre "homem e mulher", reconhecendo apenas o modelo heteronormativo de composição familiar. Curiosa é a sistemática da Constituição equatoriana, que em seu artigo 67 prevê que "se reconoce la familia en sus diversos tipos"; e, logo depois, no mesmo artigo, indica que o casamento é a união entre homem e mulher. O que se pode deduzir disso, em conjunto com as normas que regulam a união estável, é que a Carta Magna do Equador estaria reconhecendo o status de família arranjos monoparentais e, talvez, a outros casais que não apenas os heterossexuais, mas limitando o instituto do casamento somente à tradicional construção heteronormativa.

\section{Tabela 3 - Disposição das Constituições Acerca do Casamento}

\begin{tabular}{cccc}
\hline Classificação & Sem Disposição & $\begin{array}{c}\text { Disposições } \\
\text { Específicas no que se } \\
\text { Refere ao Gênero }\end{array}$ & $\begin{array}{c}\text { Disposições Neutras } \\
\text { no que se Refere ao } \\
\text { Gênero }\end{array}$ \\
\hline \multirow{2}{*}{ Países } & $\begin{array}{c}\text { Argentina, Brasil*, } \\
\text { Chile, Guiana, } \\
\text { Peru, Suriname, }\end{array}$ & $\begin{array}{c}\text { Bolívia, Colômbia, } \\
\text { Equador, Paraguai e }\end{array}$ & \\
& Uruguai e México & Venezuela & \\
\hline
\end{tabular}

Fonte: autoria própria

Quando se volta a análise para o instituto jurídico da união estável (ou união de fato), o cenário se altera ligeiramente. Conforme exposto na Tabela 4 , a terceira coluna, antes vazia, passa a contar com a presença do Equador, cujo texto constitucional prevê, em seu artigo 68, que "la unión estable y monogámica entre dos personas (...) generará los mismos derechos y obligaciones que tienen las familias constituidas mediante matrimonio". Com essa disposição, não há qualquer possibilidade de se argumentar que a Constituição equatoriana não permitiria a união civil, por meio do instituto da união estável, para casais homossexuais. O conjunto textual é bem nítido ao dispor que o casamento se dá entre "homem e mulher" e a união estável entre "pessoas", além de indicar que é reconhecida a família em seus diversos tipos. O legislador constituinte teve a intenção de incluir os casais homoafetivos nessa possibilidade de união, demonstrando-se a previsão mais progressista na temática dentre todos os países analisados.

Contudo, a desconstrução do ordenamento equatoriano apresenta uma séria limitação. Além de possibilitar a extensão apenas da união estável (e não do casamento), a Constituição, no mesmo artigo 68, prevê expressamente que a adoção somente poderá ser realizada por casais 
heterossexuais $^{10}$, não deixando qualquer margem para uma interpretação hermenêutica diferenciada, o que enseja grande retrocesso no tangente aos direitos dos LGBTIs.

Todos os demais países se enquadram nas duas primeiras classificações e cinco deles preveem de maneira expressa que a união estável se dá entre homem e mulher. Ademais, salientase que dois países que não apresentavam disposição acerca do casamento, Brasil e Peru, indicam explicitamente que esse segundo tipo de união ocorrerá entre homem e mulher.

\section{Tabela 4 - Disposição das Constituições Acerca da União Estável}

\begin{tabular}{cccc}
\hline Classificação & Sem Disposição & $\begin{array}{c}\text { Disposições } \\
\text { Específicas no que se } \\
\text { Refere ao Gênero }\end{array}$ & $\begin{array}{c}\text { Disposições Neutras } \\
\text { no que se Refere ao } \\
\text { Gênero }\end{array}$ \\
\hline \multirow{2}{*}{ Países } & $\begin{array}{c}\text { Argentina, Chile, } \\
\text { Colômbia, Guiana, } \\
\text { Suriname, Uruguai } \\
\text { e México }\end{array}$ & $\begin{array}{c}\text { Brasil, Bolívia, } \\
\text { Paraguai, Peru e } \\
\text { Venezuela }\end{array}$ & Equador \\
\hline
\end{tabular}

Fonte: autoria própria

Desse modo, é perceptível que proteção dos direitos LGBTIs a partir do critério desta seção (que comporta, meramente, a ausência de restrição com relação às uniões civis) é praticamente nula. À exceção da Constituição equatoriana (e apenas no tangente à união estável), todas as demais cartas de direitos analisadas ou não apresentavam qualquer disposição relativa à matéria ou restringiam o âmbito de possibilidades a uma realidade heteronormativa.

\subsection{Demais previsões}

Como mencionado no início desta seção, além do exame dos três critérios até agora desenvolvidos, realizou-se a leitura integral dos textos constitucionais, na busca por outras disposições normativas relativas à população LGBTI, que não conseguiriam ser antecipadas. Nesse sentido, destaques adicionais podem ser feitos.

O primeiro deles diz respeito à Constituição boliviana, que em seu artigo 66 consolida a garantia de exercício dos direitos sexuais e reprodutivos. Como já destacado, os direitos sexuais são uma categoria que se transformou ao longo da história, consolidando-se simbolicamente como uma forma de proteção aos direitos LGBTIs. Embora pareça ter uma característica muito principiológica e indeterminada, trata-se de importante previsão textual que pode ser utilizada para tutelar amplamente os mais diversos direitos dos e das LGBTIs.

Por outro lado, a Lei Fundamental do Equador se mostrou pioneira no contexto latinoamericano, sendo a única a prever um direito substantivo específico a essa população, que se enquadra como uma forma de proteção positiva e direta. Nesse sentido, seu artigo 66, inciso 9, garante o direito de escolha livre e segura da orientação sexual. Sem adentrar na discussão acerca da utilização da palavra "escolha", o dispositivo estabelece uma tutela sem precedentes no direito constitucional da região. Além disso, o artigo 83, inciso 14, do mesmo documento, consolida o dever de os equatorianos "respeitarem e reconhecerem" a "orientación e identidad sexual (sic)".

O texto equatoriano sustenta, ainda, em seu artigo 21, o direito à liberdade estética, previsão que foi incluída em virtude da persistência do movimento trans do país na assembleia constituinte. Esse direito é mais uma importante via de tutela da população LGBTI, mas em especial das pessoas trans. Isso porque, ao garantir a liberdade estética, tutela-se a possibilidade de

\footnotetext{
${ }^{10}$ A parte final do artigo 68 da Constituição equatoriana dispõe: "la adopción corresponderá sólo a parejas de distinto
} sexo". 
as pessoas transgredirem os padrões tradicionalmente impostos aos gêneros feminino e masculino, principalmente com relação à vestimenta e à aparência corporal.

Finalmente, o artigo 347, inciso IV, da Constituição equatoriana, estabelece o direito à educação sexual. Embora tal previsão possa ser interpretada de modo a perpetuar apenas uma educação sob o prisma da heterosexualidade, mostra-se como importante rompimento com o tabu da sexualidade.

Utilizando a mesma metodologia de regras de inferências já descrita, é possível tentar apresentar um motivo do porquê a previsão de direitos LGBTIs apareceu nas constituições do México, Equador e Bolívia e não nas outras. A tese é de que a previsão está relacionada à data de promulgação do texto constitucional. Isto é, de que apenas as constituições mais recentes iriam apresentar esse tipo de norma. Nesse caso, a variante principal seria a data (mais recente) do texto constitucional; enquanto a variante dependente seria a previsão normativa de direitos aos LGBTIs. Desse modo, como pode ser constatado na Tabela 5 as constituições mais recentes são justamente as do Equador e da Bolívia. Por outro lado, a vedação à discriminação em função de "preferências sexuales" no documento mexicano foi introduzida por emenda apenas no ano de 2011. Sendo assim, parece haver uma relação com a data de promulgação e avanço da norma. Algo que já era de relativamente fácil vislumbre, uma vez que, quanto mais novo o texto, mais fácil sua influência por ideais mais progressistas do que aqueles prevalentes no século $\mathrm{XX}^{11}$.

\section{Tabela 5 - Data de Promulgação dos Textos Constitucionais}

\begin{tabular}{ll}
\hline País & Data de Promulgação da Constituição \\
\hline Argentina & 1853 (última reforma em 1994) \\
\hline Bolívia & 2009 \\
\hline Brasil & 1988 \\
\hline Chile & 1980 \\
\hline Colômbia & 1991 \\
\hline Equador & 2008 \\
\hline Guiana & 1980 \\
\hline México & $1917^{12}$ \\
\hline Paraguai & 1992 \\
\hline Peru & 1993 \\
\hline Suriname & 1987 (última reforma em 1992) \\
\hline Uruguai & 1967 (última reforma plebiscitária em 2004) \\
\hline Venezuela & 1999 \\
\hline
\end{tabular}

Fonte: autoria própria

Ademais, outro fator que pode ser apontado, especificamente com relação à realidade equatoriana, é o protagonismo da sociedade civil. Nesse país, a aprovação e até a lembrança da maioria dessas previsões se deveu a intenso trabalho de lobby realizado na assembleia constituinte, especialmente pelas integrantes da organização Proyecto Transgénero ${ }^{13}$, que atuaram diretamente junto às e aos parlamentares (LIND; PAZMIÑO, 2009). Todavia, é possível ver que a influência

\footnotetext{
${ }^{11}$ Não obstante, merece destaque a recente escalada conservadora que tem ocorrido ao redor do mundo. Desse modo, pode ser que um novo texto constitucional, que viesse a ser aprovado hoje, não apresentasse previsões tão favoráveis aos LGBTIs. Isso tem sido visto, principalmente, por meio das organizações de parlamentares religiosos, como ocorre no Brasil com a Frente Parlamentar Evangélica (FPE) (VITAL; LOPES, 2012).

12 A vedação à discriminação em razão de "preferencias sexuales" apenas foi incluída no texto constitucional por emenda sancionada em 10 de junho de 2011.

${ }^{13} \mathrm{O}$ site da organização pode está disponível em: <http://www.proyecto-transgenero.org/>. Acesso em: 01 abr. 2018.
}

Revista de Direito Brasileira | Florianópolis, SC | v. 26 | n. 10 | p. 46-65 | Mai./Ago. 2020 
encontrou certas barreiras, não tendo sido capaz de excluir, por exemplo, a cláusula do artigo 68, que expressamente só permite a adoção por casais heterossexuais. Não obstante, o cenário equatoriano ilustra a importância que os movimentos sociais podem ter na criação normativa, pressionando para que se atinja um patamar mais digno para as pessoas LGBTIs.

\section{CONCLUSÃO}

Finalizadas as análises documentais, é viável que se tracem algumas conclusões acerca do problema de pesquisa desenvolvido neste trabalho. Após a investigação cuidadosa de todas as constituições, é possível afirmar sem qualquer dificuldade que a proteção constitucional conferida aos LGBTIs pelo direito constitucional latino-americano é precária, quando não completamente inexistente.

Embora todos os documentos constitucionais se mostrem avançados na proteção dos direitos das mulheres, alguns inclusive adotando uma linguagem inclusiva de gênero, não se verificou nenhuma correlação entre esse avanço e qualquer progresso na seara LGBTI, existindo, inclusive, país que adota linguagem inclusiva, mas criminaliza relações homossexuais, que é o caso da Guiana.

Apenas dois países (Equador e Bolívia) oferecem proteção aos indivíduos contra discriminação com base em orientação sexual e identidade de gênero simultaneamente. E somente mais um (México) o faz sustentado exclusivamente com fundamento na sexualidade. Com destaque para o fato de que a previsão na Constituição mexicana apenas passou a vigorar a partir de emenda constitucional de 10 de junho de 2011.

Com relação à possibilidade de união civil, esperava-se apenas que as constituições adotassem uma linguagem neutra de gênero e, portanto, não constituíssem restrição ao direito de união dos homossexuais, mas a situação encontrada foi ainda pior. Nenhum país, dentre os que regulam a questão em seu texto constitucional, adota esse tipo de disposição com relação ao casamento, tendo todos eles previsto explicitamente que se daria entre "homem e mulher". Tampouco se inverte o encontrado nas disposições acerca da união estável: apenas o Equador utilizou uma construção textualmente aberta, indicando que essa segunda forma de união ocorre entre "pessoas".

Diante de tudo o que foi constatado, é possível eleger a Constituição equatoriana como aquela mais protetiva com relação aos direitos LGBTIs. Não só é a única cujo texto enseja a possibilidade de que uma das formas de união civil não seja exclusivamente heterossexual, como também: é um dos dois países que proíbe expressamente a discriminação em função tanto da orientação sexual, quanto da identidade de gênero; prevê, ainda, vedação à discriminação do portador de HIV; é o único país que possui um direito substantivo de caráter positivo, que garante a livre escolha da orientação sexual; também é o único a positivar uma forma complementar de proteção negativa, ao estabelecer o dever de os equatorianos e equatorianas respeitarem e reconhecerem as diferenças de orientação e identidade sexual; além de garantir constitucionalmente o direito à educação sexual e à liberdade estética.

Nesse sentido, ainda, retomando a referência ao Novo Constitucionalismo LatinoAmericano, é possível perceber que, embora não se encontrem quadros protetivos ideais nos documentos analisados, aquelas Constituições consideradas como maiores expoentes dessa corrente jurídica foram também as mais abrangentes na tutela dos direitos das pessoas LGBTIs. Assim, destaca-se que o movimento constitucional latino-americano parecia se encaminhar de modo evolutivo no reconhecimento de direitos específico às pessoas LGBTIs. Caminho, contudo, que pode acabar interrompido diante da crescente ascensão de governos conservadores na região. 


\section{REFERÊNCIAS}

AVRITZER, Leonardo. O novo constitucionalismo latino-americano: uma abordagem política. In: AVRITZER, Leonardo et al. O constitucionalismo democrático latino-americano em debate: soberania, separação de poderes e sistema de direitos. Belo Horizonte: Autêntica, 2017, p. 19-42.

BORRILLO, Daniel. Homofobia: história e crítica de um preconceito. Belo Horizonte: Autêntica Editora, 2016.

BURNHAM, Margaret A. Saving Constitutional Rights from Judicial Scrutiny: the saving clause in the law of the commonwealth caribbean. Inter-American Law Review, v. 36, n. 2 e 3, p. 249269, 2005.

BUTLER, Judith. O parentesco é sempre tido como heterossexual?. Cadernos Pagu, v. 21, p. 219-260, 2003.

CARDANO, Mario. Manual de pesquisa qualitativa: a contribuição da teoria da argumentação. Petrópolis: Vozes, 2017.

CARROLL, A.; MENDOS, L.R. State-Sponsored Homophobia - a world survey of sexual orientation laws: criminalisation, protection and recognition. Geneva: ILGA, 2017.

COMISSÃO INTERAMERICANA DE DIREITOS HUMANOS (CIDH). Violência contra pessoas lésbicas, gays, bissexuais, trans e intersexo nas Américas. Washington: OEA, 2015.

EPSTEIN, Lee; KING, Gary. Pesquisa empírica em direito: as regras de inferência. São Paulo: Direito GV, 2013.

FRASER, Nancy. Rethinking Recognition. New Left Review, London, v. 3, p. 107-120, maio-jun 2000.

From Redistribution to Recognition? Dilemmas of justice in a "postsocialist" age. In: OLSON, Kevin. Adding Insult to Injury: Nancy Fraser debates her critics. London: Verso, 2008, p. 11-41.

Scales of Justice: reimagining political space in a globalizing world. New York: Columbia University Press, 2010.

Redistribuição, Reconhecimento e Participação: por uma concepção integrada de justiça. In: SARMENTO, Daniel; IKAWA, Daniela; PIOVESAN, Flávia. Igualdade, Diferença e Direitos Humanos. Rio de Janeiro: Lumen Juris, 2010a, p. 167-189.

GRUPO GAY DA BAHIA (GGB). Mortes Violentas de LGBT no Brasil: Relatório 2017. Salvador: GGB, 2017. Disponível em: < https://homofobiamata.files.wordpress.com/2017/12/relatorio-2081.pdf>. Acesso em: 20 maio 2018.

KING, Nigel. Doing Template Analysis. In: SYMON, Gillian.; CASSEL, Catherine. Qualitative Methods in Organizational Research: core methods and current challenges. London: SAGE Publications, 2012, p. 426-450. 
LELIS, Rafael Carrano. Radiografia LGB da assembleia constituinte: uma análise quantitativa das emendas contendo o termo "orientação sexual". In: Klever Filpo; Maria Geralda Miranda; Rogerio Borba da Silva; Thiago Rodrigues Pereira. (Org.). Direitos humanos e fundamentais em perspectiva. Rio de Janeiro: Ágora21, 2019, p. 701-720.

LIND, Amy; PAZMIÑO, Sofía Argüello. Activismo LGBTIQ* y ciudadanías sexuales en el Ecuador: Un diálogo con Elizabeth Vásquez. Revista de Ciencias Sociales, n. 35, p. 97-101, 2009.

MELLO, Celso Antônio Bandeira de. O Conteúdo Jurídico do Princípio da Igualdade. São Paulo: Malheiros Editores, 2010.

MISKOLCI, Richard. Teoria Queer: um aprendizado pelas diferenças. Belo Horizonte: Autêntica Editora: UFOP, Universidade Federal de Ouro Preto, 2016.

PAIVA, Vera. A psicologia redescobrirá a sexualidade?. Psicologia em Estudo, v. 13, n. 4, p. 641-651, 2008.

RIOS, Roger Raupp. Direito da Antidiscriminação, Sexo, Sexualidade e Gênero: a compreensão da proibição constitucional de discriminação por motivo de sexo. In: SARMENTO, Daniel; IKAWA, Daniela; PIOVESAN, Flávia. Igualdade, Diferença e Direitos Humanos. Rio de Janeiro: Lumen Juris, 2010, p. 695-717.

As uniões homossexuais e a "família homoafetiva": o direito de família como instrumento de adaptação e conservadorismo ou a possibilidade de sua transformação e inovação. Civilistica.com, v. 2, n. 2, p. 01-21, 2013.

SANTOS, Boaventura de Souza. Refundación del Estado en América Latina: Perspectivas desde una epistemología del Sur. Lima: Instituto Internacional de Derecho y Sociedad, 2010. SILVA, Virgílio Afonso da. La unión entre personas del mismo género: ¿cuán importantes son los textos y las instituciones?. Discusiones, v. 15, n. 2, p. 171-203, 2014.

SIMÕES, Júlio Assis; FACCHINI, Regina. Na trilha do arco-íris: do movimento homossexual ao LGBT. São Paulo: Editora Fundação Perseu Abramo, 2009.

Transgender Europe (TGEU). Trans Murder Monitoring results: TMM IDAHOT 2016 Update, 2016. Disponível em: <https://transrespect.org/wpcontent/uploads/2016/05/TvT_TMM_IDAHOT2016_Tables_EN.pdf>. Acesso em: 25 mar. 2018.

THE YOGYAKARTA PRINCIPLES PLUS 10 (YP10). Additional principles and state obligations on the application of international human rights law in relation to sexual orientation, gender identity, gender expression and sex characteristics to complement the Yogyakarta Principles. Geneva: nov. 2017. Disponível em: <http://yogyakartaprinciples.org/wpcontent/uploads/2017/11/A5_yogyakartaWEB-2.pdf>. Acesso em: 03 fev. 2018

VIEIRA, José Ribas et al. Impasses e alternativas em 200 anos de constitucionalismo latinoamericano. Revista de Estudos Constitucionais, Hermenêutica e Teoria do Direito, v. 5, n. 2, p. 122-132, 2013. 
VITAL, Christina; LOPES, Paulo Victor Leite. Religião e Política: uma análise da atuação dos parlamentares evangélicos sobre direitos das mulheres e de LGBTs no Brasil. Rio de Janeiro: Fundação Heinrich Böll, 2012.

WILSON, Geoffrey. Comparative Legal Scholarship. In: MCCONVILLE, Mike; CHUI, Wing Hong. Research Methods for Law. Edinburgh: Edinburgh University Press, p. 87-103, 2007.

WINTEMUTE, Robert. Same-sex love and Indian penal code $\$ 377$ : an important rights issue for India. NUJS Law Review, v. 31, n. 4, p. 31-65, 2011. 